precautionary vigilance over unbridled freedom of action.

The IOM panel, co-chaired by Stanley Lemon of the University of Texas at Galveston, envisages a global biosecurity network not dissimilar to ProMED-mail, a web- and e-mail-based network that helps public-health specialists worldwide share information.

Such a network would enable scientists to exchange views on questions, such as when the risks associated with a particular experiment outweigh its potential benefits. It is extremely difficult to make such calls, as was demonstrated most recently by last year's debate over a paper that modelled a toxin attack on the US milk supply (see Nature 435, 855; 2005). The Lemon report points out that a grassroots network of scientists interested in bioterrorism issues would at least get a broader section of the community talking and thinking about such issues.

The report also emphasizes the fact that the scope of the bioweapons threat is far wider than commonly imagined. We are entering an era in which scientists will be able to design and build organisms for purposes of their choice, for good or ill. The IOM rightly advises US policy-makers to broaden their consideration of biodefence beyond the 50-or-so 'select agents' that the US health department has concentrated on until now. That will involve greater consultation with researchers who operate in areas ranging from genetics to nanotechnology, and who do not consider themselves to be involved in biodefence work.

Finally, the IOM calls for more input of up-to-date scientific advice at the US national security agencies, such as the Central Intelligence Agency and the National Security Agency, who are charged with looking out for bioterror-related activity. The work of these agencies is classified, and the report calls for the establishment of a scientific advisory board, with appropriate clearances, to help the agencies interpret the data they collect. This idea was also proposed last March by a commission set up by President George Bush to look at the spy agencies' capabilities in countering weapons of mass destruction. It should be implemented as soon as is practicable.

The containment of potentially dangerous biological knowledge is a formidable challenge - intrinsically even tougher than blocking the proliferation of nuclear weapons. But it is not one that the scientific community can wish away. The IOM panel has performed a valuable service by highlighting some ways in which biologists can step up to it.

\section{Japan's research conduct}

\section{A framework is required for investigations into scientific misconduct in Japan.}

or the past two years, researchers in Japan and elsewhere have been frustrated in their attempts to reproduce a set of RNA interference papers co-authored by Kazunari Taira, a biochemist at the University of Tokyo (see Nature 439, 514; 2006).

The university has now established a committee that will look into Taira's experiments. But some of those involved in the investigation admit that it may not get to the bottom of the issue. The episode points to a lack of preparation for such cases on the part of the university by far the country's largest and most prestigious research institution. Fault also lies with the government, which has failed to establish a robust framework for investigating alleged scientific misconduct. The lack of such a national framework leaves Japan's universities to look into such allegations independently, and on an ad hoc basis.

The case came to the fore last spring, when the RNA Society of Japan, prompted by members' complaints, requested the University of Tokyo to look into 12 papers produced by Taira's research team. Asked to provide evidence to back up the papers, the team said that it no longer had the notebooks containing the experimental data and that a computer, to which the data had been transferred, had broken down and the data had been erased. The team then struggled to comply with a request that some of its experiments be repeated. Taira has publicly blamed his co-author, Tokyo University biochemist Hiroaki Kawasaki, for mislaying the data. Both men deny any wrongdoing.

Members of a preliminary committee looking into the case complained that they were not given authority to investigate properly. A new committee set up two weeks ago says it will conduct interviews with many researchers on the team. But e-mail exchanges among the researchers will not be used as evidence, and one committee member admits that, without the notebooks, a determination of whether scientific misconduct occurred is improbable. Committee member Kimihiko Hirao, head the university's school of engineering, says that, unlike the South Korean case of Seoul National University's Woo Suk Hwang, where inside informers pushed the investigation along, they have no direct allegations of misconduct to investigate.

Things could have gone differently. The university did not have a system for accepting and protecting whistleblowers, and therefore could not really expect inside informers to come forward even if misconduct had occurred. There are no clear rules on the penalty if documentation, such as laboratory notebooks or other materials essential to supporting experimental results, is destroyed. And there is no established framework within which such an investigation should proceed.

The University of Tokyo has argued that it lacks the

\section{"A country of Japan's scientific muscle ought to have set up a body to train universities to investigate fraud."}

power to investigate the case properly. But two years ago, like Japan's other national universities, it received widespread autonomy from the government. It should use this autonomy to recover from the damage done to its reputation by its unsteady response to this case.

Universities in the United States and Europe have, sometimes with the aid of national misconduct offices such as the US Office of Research Integrity, developed mechanisms allowing them to investigate such cases discretely and comprehensively. A country of Japan's scientific muscle ought to have set up such a body to train universities to investigate fraud and, where appropriate, to administer national sanctions.

Investigations into research misconduct are invariably uncomfortable for all concerned. But the alternative is the pervasive aroma left by cases such as this one, in which the researchers and institutions are neither convicted nor exonerated. It is to be hoped that the investigation now belatedly under way will clear the air. 